\title{
Development of an Integrated SDSS for Coastal Risks Monitoring and Assessment
}

\author{
Greco Michele ${ }^{1 *}$, Martino Giovanni ${ }^{1}$, Guariglia Annibale ${ }^{2}$, Trivigno Lucia ${ }^{3}$, Sansanelli Vito ${ }^{2}$ and Losurdo Angela ${ }^{2}$ \\ ${ }^{1}$ Engineering School, University of Basilicata, Potenza, Italy \\ ${ }^{2}$ Geocart Srl, Viale dell Basento, Potenza, Italy \\ ${ }^{3}$ Centre of Integrated Geomorphology in Mediterranean Area, Via F. Baracca, Potenza, Italy
}

\begin{abstract}
The first results of the regional Operative Project (OP) "Implementation of hydraulic risk forecast and prevention system", as part of the extended operative programme MATER aimed to develop a methodology for environmental and territorial analysis related to the exploitation of natural resources, are shown in the present paper. The main target deals with the development and implementation of a Spatial Decision Support System (SDSS) platform for coastal risk forecasting and prevention through the integration of multisource satellite data (Sentinel-1, Sentinel-2 and COSMO Sky Med) coupled with post processing open source hydrodynamic models. The processing results include the coastline and back-dune vegetation mapping, rocky coast movements detection as well as new landfills, buildings and spills derived by the implementation of innovative images segmentation techniques, multi-band change-detection and PSInSAR (Persistent Scattered Interferometric Synthetic Aperture Radar) typologies. The SDSS provides significant advantage of cyclical production and/or updating in phase with satellite data acquisition frequency. Further, through self-consistent applicative tools, provided with proper graphical interface developed in IDL and integrated in SDSS, it is possible to display and automatically extract the coastline sequence from Sentinel-1 data, compare two shoreline acquisitions, even if multi-sources, and calculate the coastal erosion and aggradation.

Finally, some interoperable tools for morpho-hydrodynamic modelling assimilation have been developed and implemented in order to reproduce flooding risk scenarios for the coastal resilience assessment at different return time. For such a purpose, in the start-up phase, Delft3D (Deltares- NL) was employed for storm surge modelling, coastal morphological evolution and coastal inundation analyses. The SDSS is interconnected with a friendly and intuitive WebGIS compatible to the Regional Spatial Data Infrastructure.
\end{abstract}

Keywords: Spatial decision support systems; Synthetic aperture radar; Change-detection; Coastal risk; Hydrodynamic modelling

\section{Introduction}

The high population density concentrated on the coastline and the progressive growth of economic and touristic activities linked to the use of marine and coastal resources are some of the issues threatening the delicate natural framework of sea-side areas and in-shore coasts as well as the objective issues related to the management of coastal risks mainly concerning erosion and flooding.

For Basilicata (Southern Italy), which has about $75 \mathrm{~km}$ of coastline with a varied morphologies (rocky with cliffs, sandy and stony), the coastal system is a worthy resource of highly natural and landscaping significance as well as being valuable and necessary to protect and promote through an economic and social natural-friendly development.

The problems of coastal erosion occurring over the years mainly induced by drastic reduction of river sediment yield due to distributed interventions along rivers, dam construction, reservoir management and rehabilitation [1] as well as an increase in anthropic pressure due to touristic and productive settlements [2]. The real extension of such a phenomena have sensitively increased public awareness to the opportunity to allocate resources and interventions addressed to risk prevention rather than emergency management. Such a smart governance approach might be based on an all-embracing and systematic analysis of coastal area vulnerability, both local and systemic, in order to identify proper mitigation and contrast measures necessary to cope with sea aggression and seriously compromising the Lucanian coast [3].

In such a context, mostly sensitive and vulnerable, appropriate resources to improve and implement monitoring systems, both conventional and innovative, as well as modelling procedures able to continuously support the planning and management activities must be developed and employed. The paper presents preliminary functional results of the Regional Operative Project MATER-aimed at developing a "Methodology of environmental and territorial analysis for the exploitation of natural resources" in which the first operational results is the definition and implementation of a Spatial Decision Support System for hydraulic-coastal risk forecast and prevention. The main frame deals with the integration and use of ground and remote earth observation data, with particular reference to new satellite missions, such as Sentinel-1 and 2 [4], as well as COSMOSkyMed.

In particular, among the operative products, the project envisages the structuring and implementation of an expandable SDSS based on open-data catalogues, able to manage and display both the basic information, including the relative metadata, and the elaboration and processing results with open-source change-detecting codes and hydro-morphological modelling. The SDSS includes the development of integrative methodologies for systematic and continuous coastal

*Corresponding author: Greco Michele, Engineering School, University of Basilicata, Potenza, Italy, Tel: +390971205199; Fax: +393293179389; E-mail: michele.greco@unibas.it

Received July 14, 2017; Accepted August 05, 2017; Published August 18, 2017

Citation: Greco M, Martino G, Guariglia A, Trivigno I, Sansanelli V, et al. (2017) Development of an Integrated SDSS for Coastal Risks Monitoring and Assessment. J Coast Zone Manag 20: 446. doi: 10.4172/2473-3350.1000446

Copyright: ( 2017 Michele G, et al. This is an open-access article distributed under the terms of the Creative Commons Attribution License, which permits unrestricted use, distribution, and reproduction in any medium, provided the original author and source are credited. 
monitoring, interfaced in an open source WebGIS environment dialoguing with the Regional Spatial Data Infrastructure (RSDI). The SDSS provides the integration of ground and remotely sensed data with Open Source Information technologies for the basic and advanced analyses and web publishing of geographic data for a simple and intuitive end-user consultation. Geographic data are processed through the interoperability WMS (Web Map Service) standards defined by the OGC (Open Geospatial Consortium) by implementing processing techniques for the production of territorial information, based on PSInSAR and Change Detection methodologies widely developed and well-established in the analysis of radar data aimed to extended targets [5].

The validation activity of the developed procedures is based on the comparison with the ground data acquired mainly by aerial surveys, carried on with a multi-sensor platform such as metric camera, thermal camera, hyperspectral systems and Laser. Such validated information are data input of morpho-hydrodynamic numerical models in order to create several critical risk scenarios for coastal flooding and erosion.

\section{Implementation of the GIS-DSS Systems}

Decision Support Systems (DSS) are a specific class of computerized information tools and systems, which allow decision-making activities. In general, DSS are interactive computer-based systems and subsystems proposed to assist decision makers' use of communication technologies, data, documents, knowledge and/or models to identify and solve problems and make choices [6]. They should help in formulating alternatives, accessing data, running numerical and/or conceptual assessment models, displaying and interpreting results [7]. There is a wide range of spatially distributed information on characteristic coastal areas, such as shoreline, beach morphology, land use/cover, topography, etc., and for this reason DSS used in such analyses are classified as Spatial Decision Support Systems (SDSS). The Geographic Information System (GIS) is, then, considered a generator for SDSS because of its power and efficient functions to store, retrieve, analyse, manipulate as well as display large volumes of spatial digital data and create thematic maps or logical frameworks. The analysis of functional and architectural system requirements, supported by the research and identification of the reference solutions within the engineering software led to the design of a scalable and modular architecture.

The UML diagram set out in Figure 1 represents the architecture modelling of the MATER system, highlighting its modularity. Inside it, indeed, both software components and internal and external interfaces of the system can be identified.

The system components are:

- $\quad$ SERVER FTP enabling file storage;

- $\quad$ CATALOGER which allows users to publish a catalogue of the descriptions of data sets (metadata) for the web such that they can be queried and updated by the clients of the catalogue;

- $\quad$ WEBGIS that is a geographic information system (GIS) published on Internet, namely a mapping service making data available on the web;

- $\quad$ DSS (Decision Support System) that is a software system for support of decisions that, on the basis of algorithms, allow us to extract data useful information for decision- making from available.

In a general detail, the SDSS are new web-based software systems which provide the user with a series of functions of data and model

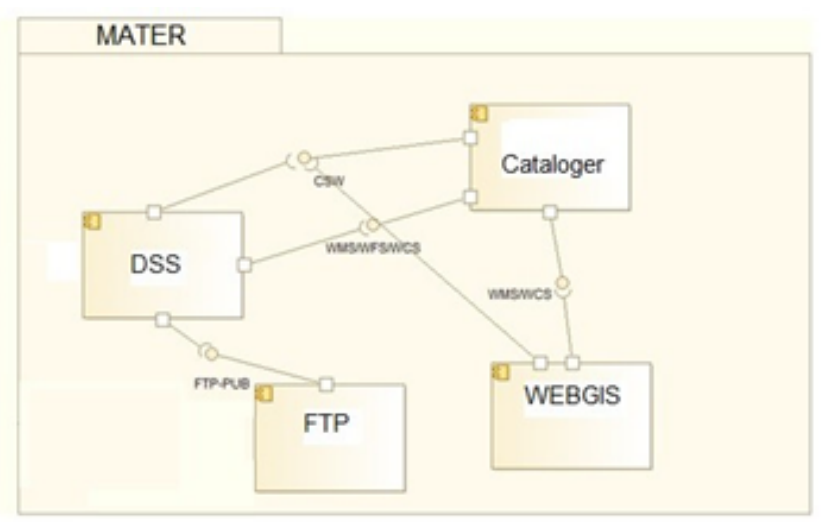

Figure 1: Architecture software.

analyses in an interactive, and possibly simple and expeditive way, and allow us to increase the efficiency and robustness of the decisionmaking proposing real-time-alternative scenario in the time-space domain [8].

Comparing both systems, traditional computer based SDSS and web- based SDSS, the last ones present several advantages [7-14], such as:

- Centralized control inducing lower costs for hardware, software, distribution, maintenance and training;

- Greater efficiency in model improvement and data update, ever more if real time information and data are employed;

- Global, quick and user-friendly accessibility;

- Independent platform even through virtual machine.

These features facilitate a wide community of stakeholders to access and participate in the public planning and decision-making processes, which can fruitfully impact the quality of their work even improving public awareness of the existence of spatial digital data and scientific models. In such a framework, a DSS evolution is made up of SDSS having the added value of the explicit consideration of the spatial dimension of decision-making problems which are intrinsic features to take into account in territorial system management and transformation. Thus, the GIS-DSS of the MATER platform is set up as a SDSS. This system has been deliberately implemented on the basis of open-source solutions extending its functionality.

Therefore, previous study and analysis of the state-of-the-art of available open-source solutions in GIS environment have been carried on addressing the QuantumGIS (QGIS). QGIS, indeed, is an opensource system released under GNU General Public License and it is an official project of the Open Source Geospatial Foundation (OSGeo). The software is available for Linux, Unix, Mac OSX, Windows and Android platforms and supports several formats of spatial data. Furthermore, it allows us to process on spatial databases offering vector analysis tools, geoprocessing and database management [15]. Finally, it is possible to adapt QGIS to specific needs due to the extensible architecture of plugins that can be created through specific libraries. The SDSS module has been implemented in Python (ver. 2.7) and set up as plug-in of QGIS (ver. 2.10 Pisa) on OS Windows 7 pro 64 bit.

\section{Implemented Information Layers-Tools and Plug-In}

Under the OP, the QGIS project has been implemented containing 
Several informative layers, namely of new acquisition and so updatable by the user. The implemented information layers are related to the multisource data as reported in Table 1.

It should be underlined that in line with storage function, the system is able to process data through specific tools designated for such a purpose. For instance, the Lidar Data were not directly pre-loaded into the system, because QGIS does not allow direct displaying in the native format and so, within the project, an ad hoc plug-in has been designated. The plug-in, named LAStoDEM Compare, manages the work-flow that, from the data in Lidar format, led to create the DEM in Raster format as well as the management and query of the extracted data.

The main advanced tools and plug-in can be summarised as follows:

\section{Management of geographic datum}

As one of the GIS system features is the management of information layers in different coordinate systems. The project enforces the management and processing procedure of the coordinates in QGIS environment in order to ensure the download and management of available, namely future, multisource data as specifically as possible.

The management of geographic datum in QGIS environment is entrusted to an "on-the-fly" testing algorithm(OTF) which automatically manages the datum conversions and geographic projections among information layers in different coordinate systems adopting some specific libraries produced and distributed by OSGeo.

These libraries contain, for almost all the reference systems, global and local, the geodetic parameters such as projection, ellipsoid, false origins and scale factors, etc., useful for the automatic re-screening of the associated geographic data. This enhances the user to use geographic information coherently to several reference systems.

However, the precision on which data are re-developed, and thus overlapped, depends on the source data accuracy, moving from rigorous transformations for the most widespread global systems to approximate transformations for some local systems [16].

Considering that the most common systems in Italy are the Gauss-Boaga and ETRF89/ETRF2000 projections /ETRF2000, several
GIS software including QGIS use simplified algorithms based on 7-parameters-Helmert transformation, and provide approximate transformation values with several meters of error according to altimetry.

Therefore, a new library has been published by recalculating these parameters in order to improve the precision of transformations at a regional level. The application of recalculated parameters on a sample of transformed points has led to average deviations in position of about $30 \mathrm{~cm}$ on the converted points referring to the grids of the Military Geographical Institute [2].

\section{Self-extraction of the coastline}

The processing results include the coastline mapping, the back-dune vegetation mapping, the detection of rocky coast movements as well as new landfills, new buildings and spills. They have been produced by applying innovative images segmentation techniques, multi-band change-detection and PSInSAR (Persistent Scattered Interferometric Synthetic Aperture Radar) typologies, having the significant advantage of cyclical production and/or update with the same acquisition frequency of satellite data.

Through self-consistent applicative tools, provided with proper graphical interface developed in IDL and integrated in SDSS, and appropriate change-detection techniques, it is possible to display and automatically extract the coastline from Sentinel- 1 data. Moreover, the system is able to compare two acquisitions, also multi-sources, e.g. by highlighting and calculating the eroding areas and those progressively emerged on the beach as shown in Figures 2 and 3. The plots report the multi-source coastlines relative to the acquisitions in 1947-1949-19982001-2005-2006-2008-2011-2012-2013 and 2015 referring to the 2015 orthophoto base.

\section{Morpho-hydrodynamic modelling}

In order to reproduce possible alternative scenarios, to simulate the coastal system response at different natural and anthropic stresses, as well as to provide a valuable qualitative- quantitative support for decision-making, some tools able to make the SDSS interoperable by morpho-hydrodynamic modelling software have been developed

\begin{tabular}{|c|c|}
\hline Layers & Contents \\
\hline Framework & $\begin{array}{l}\text { All the information layers are raster type, except those of satellite data, and complain with official formats of the cartography released by } \\
\text { the Military Geographical Institute (IGM). }\end{array}$ \\
\hline Bathymetry & Archive data relative to the bathymetric campaigns in 2012 and 2015. \\
\hline Cartography & Historical data in raster format of the official IGM cartography at 25.000 edition 1949. \\
\hline DTM & $\begin{array}{l}\text { Digital terrain models in raster format derived from aerial Lidar scans of archive and new acquisition during the OP MATER } \\
\text { implementation; in details DTM refer to 2006, 2008, 2011, 2012, } 2013 \text { and } 2015 \text {, all of them have been pre-loaded. }\end{array}$ \\
\hline Shoreline & $\begin{array}{l}\text { Shoreline, in vector format produced by multisource data, both of archive and new acquisition. In particular, they have been extracted } \\
\text { according to data availability in the following order of priority: } \\
\text { Data relative to } 1947,1949,1988,2001,2005,2006,2008,2011,2012,2013,2015 \text { have been extracted. }\end{array}$ \\
\hline Orthophoto & $\begin{array}{l}\text { Information layers refer to historical and of archive orthophotos, B/W and coloured ones, obtained with analogue technologies and } \\
\text { orthophotos of latest production obtained with high-resolution digital cameras. The pre-loaded layers are relative to 1947, 1998, 2001, } \\
\qquad 2006,2008,2011,2012,2013 \text { and } 2015 .\end{array}$ \\
\hline Thermography & Aerial survey across the coastal strip performed with digital thermal camera in 2012 . \\
\hline Satellite images & $\begin{array}{l}\text { Sample catalogue containing some satellite images and related shorelines extracted from the same data. Radar Sentinel } 1 \text { and Optical } \\
\text { Sentinel } 2 \text { data have been inserted. On the satellite data no cropping operation were performed but they have been included in the full } \\
\text { coverage of the scanned images. }\end{array}$ \\
\hline Topographic survey & $\begin{array}{c}\text { Ground survey } 2015 \text { available in the form of row measured points and coastline derived from the acquired points. It has been also provided } \\
\text { and pre-loaded a similar dataset of archive, corresponding to the campaign of GPS surveys } 2006 \text {. }\end{array}$ \\
\hline Lidar Data & Laser data of archive and new campaigns are available, after a careful clipping work and geographic homogenization. \\
\hline
\end{tabular}

Table 1: Currently implemented information layers. 


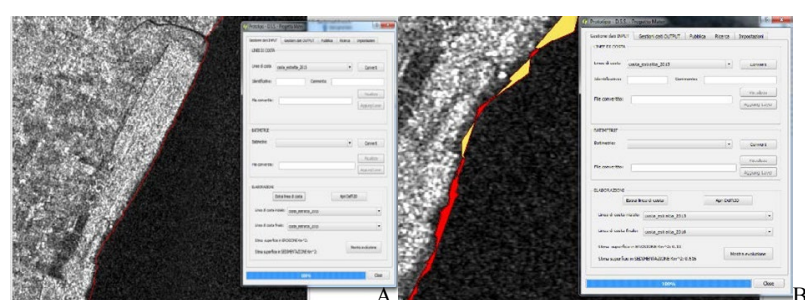

Figure 2: (A) Coastline extraction from sentinel-1 data; (B) Comparison between two available dataset.

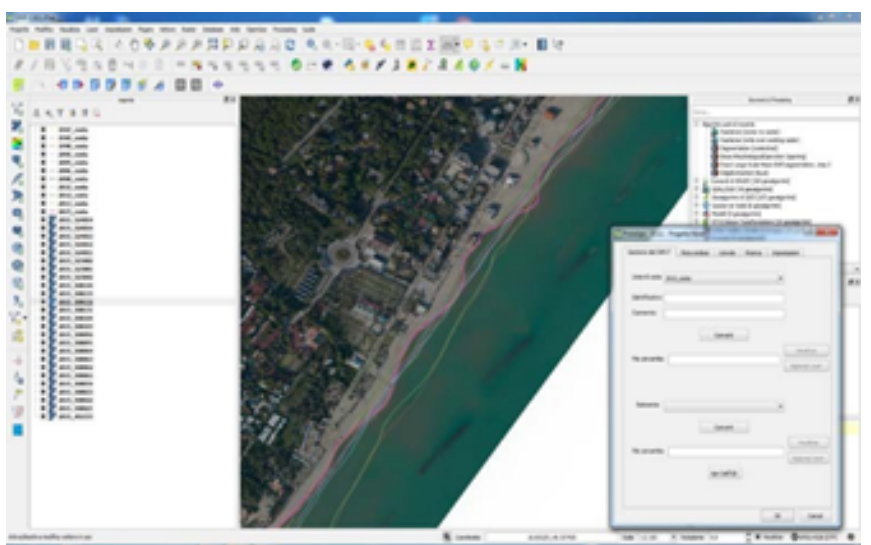

Figure 3: Graphic comparison between two multi-source coastlines on orthophoto basis.

and implemented. For such a purpose, in the start-up phase, Delft3D (Deltares- NL) was employed [4].

The Delft3D software (http://oss.deltares.nl/web/opendelft3d/ home), produced and distributed by the Research Institute Deltares $(\mathrm{NL})$, is available both in pre-compiled mode and open source, and is based on consolidated calculation algorithms resulting primarily from activities carried out by the Environmental Fluid Mechanics Section of the Faculty of Civil Engineering and Geosciences at Delft University of Technology (TUDelft-NL). The system is mainly composed of three modules grouping hydrodynamic simulation models, morphological and wave motion models as well as pre- and post-processing tools. The module relative to wave energy (Delft3d-WAVE) uses the SWAN (Simulating WAves Nearshore-TUDelft [16]), as a core processing code. This represents the state- of-the-art of so-called third-generation phaseaveraged models, able to simulate, in steady or unsteady conditions the following issues:

- Time-space propagation of wave motion.

- Shoaling and refraction for bathymetric variation and induced by currents.

- Wave generation, even considering non-linear effects due to wave overlapping.

- Energy dissipation due to the interaction between waves and seabed.

- Wave breaking and vegetation.

- Diffraction and reflection phenomena.

If necessary, the algorithm is able to process "nesting" operations, or may use different computing grids in a single run, nested one against another with a rising level definition. Such a frame results particularly useful whenever modelling of localized phenomena whenever detailed scales are required with a high computational outlay.

The hydrodynamic module, Delft3D-FLOW, is a multi-dimensional program based on Navier-Stokes equations for an incompressible fluid, under the Boussinesq assumptions for shallow water. It calculates steady or unsteady flows and transport phenomena, resulting from tidal and/or weather forcing, on a rectilinear and uniform or curvilinear grid. Further, the module is able to simulate, with a highly accurate and defined unconditionally stable procedure, both in 2DH and 3D modes, even with diffusion and transport phenomena, taking into account the time variation of physical characteristics of the fluid. Furthermore, it is coupled to the transport module which allows us to identify the sediment transport induced by coastal currents, in time and space domains [17].

The main architecture of the implemented system switches on the SDSS to communicate with Delft3D code, both in terms of input for numerical computation and collecting the corresponding output for further analysis in QGIS environment. Indeed, the coastline can automatically be extracted and forwarded to pre- and post-processing data tools available in the Delft3D package. Although, the Delft3D code has a structured and complex output format which cannot be directly managed by QGIS, the developed and implemented set-up tool working in the SDSS allows us the extraction, displaying and multi-time management of the Delft3D output data. In reference to the sea wave propagation, the SDSS deals with significant wave height, significant period, average direction of wave motion and bottom velocity, as well as some data related to the coastal processes such as bottom sediment transport, suspended sediment transport, height averaged velocity, bottom shear stress and bathymetry variation in the time domain due to erosion and deposition [18]. Figure 4 shows the simulated effects in terms of bathymetric evolution of the Basento river delta due to a storm surge which event occurred on $23^{\text {rd }}$ January 2015, while in Figures 5 and 6 the average wave propagation direction and average bottom velocity distribution are reported respectively.

\section{Web-GIS and Geo-Portal}

The INSPIRE directive 2007/2/EC (Infrastructure for Spatial Information in Europe) aimed at harmonizing the organisation, accessibility and sharing methodologies of environmental spatial information among the EU Member States in order to support the EU environmental policies. Furthermore, according to such a directive, the

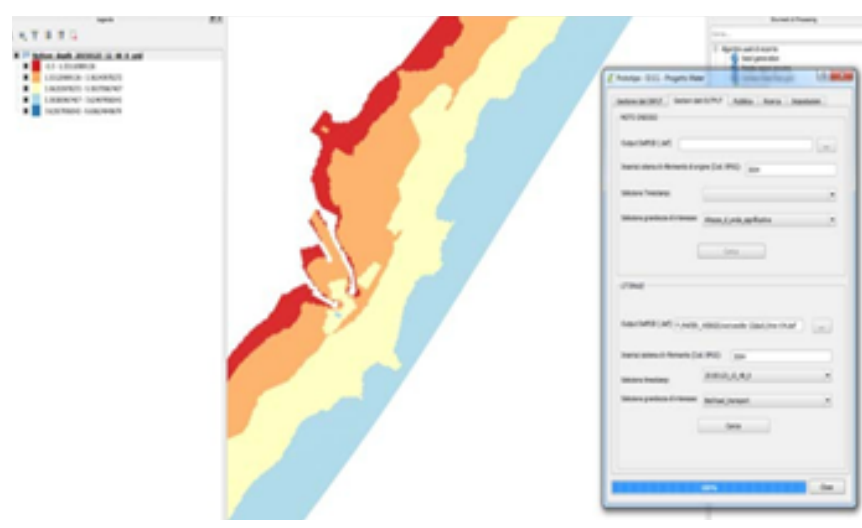

Figure 4: Time representation of bathymetry. 
Citation: Greco M, Martino G, Guariglia A, Trivigno I, Sansanelli V, et al. (2017) Development of an Integrated SDSS for Coastal Risks Monitoring and Assessment. J Coast Zone Manag 20: 446. doi: 10.4172/2473-3350.1000446

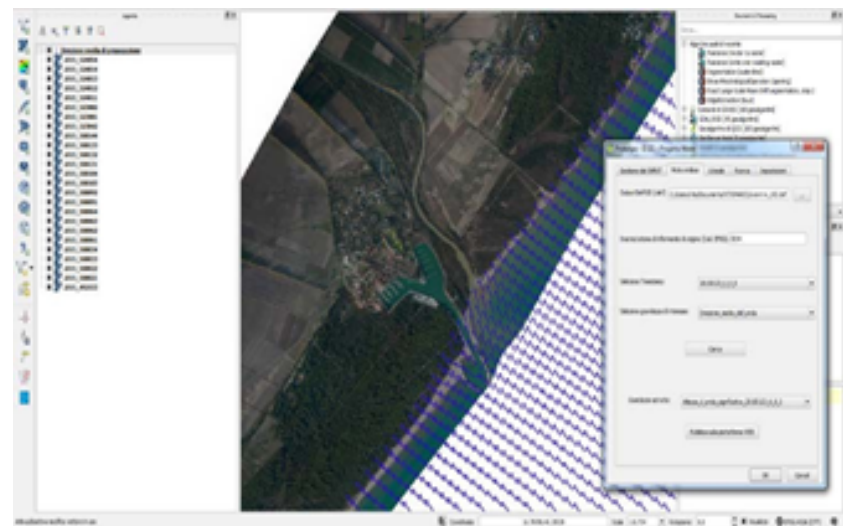

Figure 5: Time representation of the average direction of wave propagation.

information infrastructure might enable and ensure that spatial data obtained/collected from different sources should be supplied, stored and shared between users and applications. In such a context, the geoportal represents the access point to the collection, management and distribution services of geo- referenced data for territorial analyses and/or down-streaming application domains [19]. It does generally comprise a "Data Catalogue" for information download in local cockpit, providing a WebGIS tool with operational sections devoted to data publication, navigation and query. Such a WebGIS service is a geographic information system published online, which allows a mapping service of available data on the web. In such a way, it is indeed the extension into the net of specific applications designed and developed for digital cartography management. Thus, WebGIS leads the possibility of real-time interaction and the management of the access profile to the information at different levels (developer, simple user etc.). Furthermore, the access and consultation by the user is ensured even at low-level profiles without high technological upgrades.

The WebGIS-MATER platform, in such a scenario, is a Geoportal enabling publication, cataloguing, viewing and querying of information layers produced by the algorithms developed within the MATER operative project. In the framework of the INSPIRE directive, the platform should be used as SDSS and data-showing on interactive maps providing services for several integrated technologies (GeoServer for WMS/WFS/WFS-T/WCS, pycsw and CSW). Figure 7 proposes the overlap between the DTM 2015 of the Cavone delta river area and the multi-source coastlines acquired in 1998-2005-2006-2008-2011-2012 supplying general and detailed information about the delta dynamics and beach evolution for further analyses: i.e., on delta migration velocity and local induced morphological changes. Furthermore, due to the high acquisition frequency of Sentinel-1 images, it is possible to undertake extremely interesting comparative analysis of multi-source data related to the coastline relief as shown in Figure 8, in which the overlap between the Sentinel-1 image acquired on February $13^{\text {th }} 2016$ and the shorelines collected on August $29^{\text {th }} 2015$, October $4^{\text {th }} 2015$, March $11^{\text {th }} 2015$, November $3^{\text {rd }}$ and $9^{\text {th }} 2015$, December $15^{\text {th }} 2015$, January $20^{\text {th }}$ 2016 , February $1^{\text {st }}, 13^{\text {th }}$ and $19^{\text {th }} 2016$ is reported. Furthermore, due to the high acquisition frequency of Sentinel-1 images, it is possible to undertake extremely interesting comparative analysis of multi-source data related to the coastline relief as shown in Figure 8, in which the overlap between the Sentinel-1 image acquired on February $13^{\text {th }} 2016$ and the shorelines collected on August $29^{\text {th }} 2015$, October $4^{\text {th }} 2015$, March $11^{\text {th }} 2015$, November $3^{\text {rd }}$ and $9^{\text {th }} 2015$, December $15^{\text {th }} 2015$,

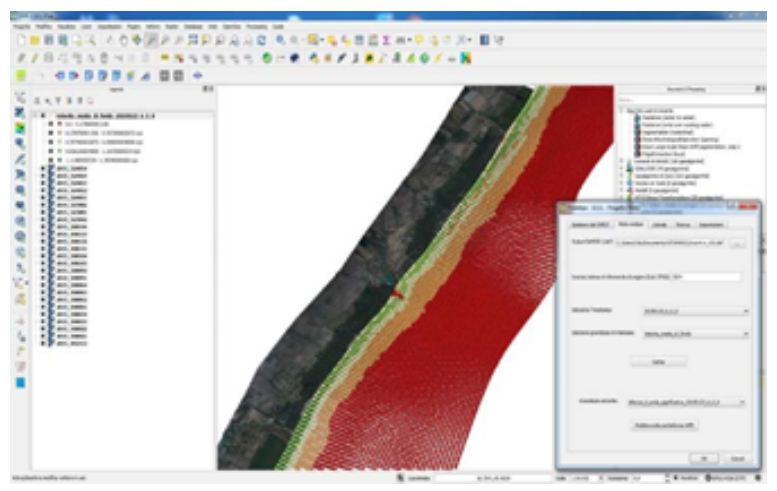

Figure 6: Time representation of the average bottom velocity.

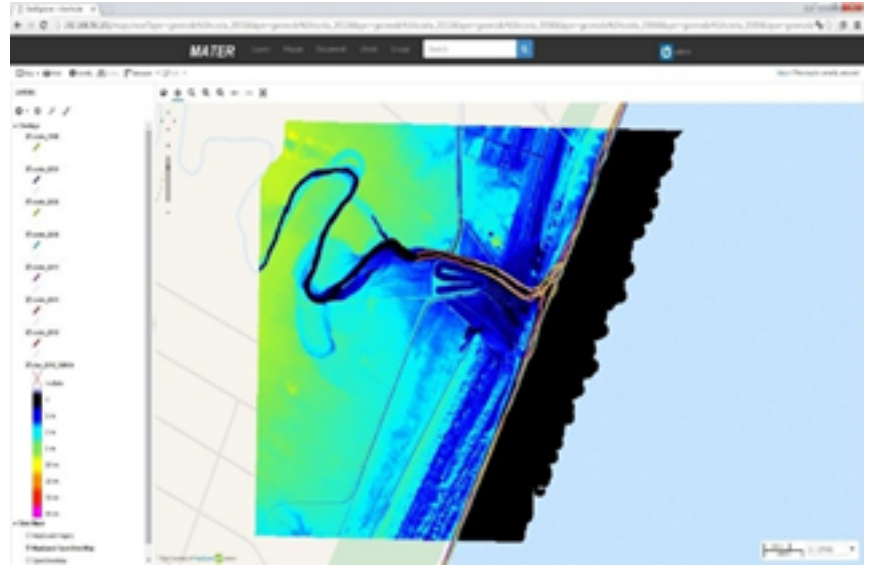

Figure 7: DTM e multi-source coastlines for the Cavone delta river.

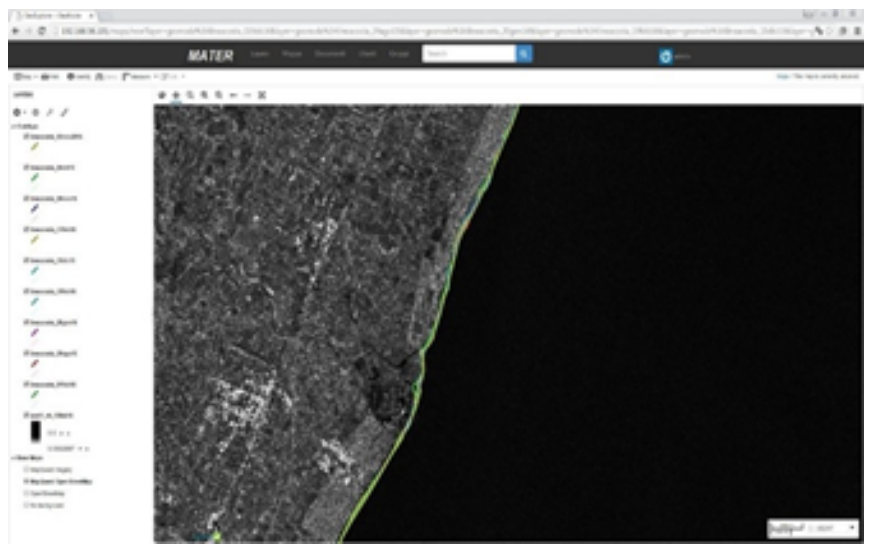

Figure 8: Sentinel-1 data and multi-source coastlines around the Agri delta river.

January $20^{\text {th }} 2016$, February $1^{\text {st }}, 13^{\text {th }}$ and $19^{\text {th }} 2016$ is reported [20].

Finally, the system also enables the viewing of maps produced by other organizations, even on their respective servers, via WMS (Web Map Service). In this way, the application is fully interoperable, ensuring both the publication of its own information layers, through OGC standards, and the integration and use of information layers derived 
Citation: Greco M, Martino G, Guariglia A, Trivigno I, Sansanelli V, et al. (2017) Development of an Integrated SDSS for Coastal Risks Monitoring and Assessment. J Coast Zone Manag 20: 446. doi: 10.4172/2473-3350.1000446

Page 6 of 6

from other sources with the same publishing standards defined by OGC as well [21].

\section{Conclusion}

The paper presents the preliminary results of the Regional Operative Project MATER aimed at developing a methodology of environmental and territorial analysis for the exploitation of natural resources and supplying the first operational products for the definition and implementation of a Spatial Decision Support System for hydrauliccoastal risk forecast and prevention. The main issue deals with the integration and use of ground and remote earth observation data, with particular reference to the new satellite missions Sentinel- 1 and 2 as well as COSMO SkyMed constellation data. Among the operative products, the project provides the structuring and implementation of an expandable SDSS based on open-data catalogues, able to manage and display both the basic information, including the relative metadata, and post-processing results with open-source change-detecting codes and hydro-morphological modelling. The SDSS includes the development of integrative methodologies for systematic and continuous coastal monitoring, interfaced in an open source WebGIS environment dialoguing with the Regional Spatial Data Infrastructure (RSDI) in compliance with INSPIRE Directive. The SDSS also supplies the integration of ground and remotely sensed data with open-source information technologies, for the basic and advanced analyses, and web publishing of geographic data for a simple and intuitive end-user consultation.

\section{References}

1. Greco M, Martino G (2014) Assessment of maritime erosion index for lonicLucanian coast. Engineering Geology for Society and Territory: Marine and Coastal Processes 4: 41-44.

2. Greco M, Martino G (2014) Modelling of coastal infrastructure and delta river interaction on ionic Lucanian littoral. Procedia Engineering 70: 763-772.

3. Greco M, Martino G (2016) Vulnerability assessment or preliminary flood risk mapping and management in coastal areas. Natural Hazards 82: 7-26.

4. Hajduch G, Bourbigot M, Johnsen H, Piantanida R, Poullaouec J, et al. (2015) Sentinel-1 product specification.

5. Losurdo A, Marzo C, Guariglia A (2015) New change detection technique applied to Cosmo-SkyMed stripmap Himage data. Proceeding of "Fringe 2015 Workshop", Frascati, ItalY. P. 731.
6. Power JD (2002) Building web-based decision support systems. Studies in Informatics and Control 11: 291-302.

7. Paz JO, Batchelor WD, Pedersen P (2004) WebGro: A web-based soybean management decision support system. Agro J 96: 1771- 1779.

8. Peng ZR, Tsou MH (2003) Internet GIS: Distributed geographic information services for the internet and wireless networks. John Wiley \& Sons, Hoboken.

9. Wang L, Cheng Q (2006) Web-based collaborative decision support services Concept, challenges and application. Proceedings of the ISPRS Vienna 2006 Symposium, Vienna. pp: 12-14.

10. Greco M, Mauro A, Mirauda D, Sole A, Vita M, et al. (2004) Integrated monitoring system of littoral and fluvial sediment transport in Basilicata. Costal Environment V, incorporating Oil Spill Studies, Book Series: Environmental studies series Fifth International Conference on Environmental Problems in Coastal Regions 10: 199-207.

11. Carone MT, Greco M, Molino B (2006) A sediment-filter ecosystem for reservoir rehabilitation. Ecological Engineering 26: 182-189.

12. Deltares (2013) Delft 3D user manuals deltares.

13. European Spatial Agency (2013) Sentinel-1 user handbook, Sentinel-1 Team GMES-S10P-EOPG-TN.

14. Booij N, Ris RC, Holthuijsen LH (1999) A third-generation wave model for coastal regions, Part I, Model description and validation. J Geophys Res 4: 7649-7666.

15. Dymond RL, Regmi B, Lohani VK, Dietz R (2004) Interdisciplinary web-enabled spatial decision support system for watershed management. J Water Res PI Manag 130: 290-300.

16. Miller R, Guertin DP, Heilman P (2003) An internet-based spatial decision support system for rangeland watershed management. Proceedings of the $1 \mathrm{st}$ Interagency Conference on Research in the Watersheds, Benson. p. 730.

17. Choi JB, Engel A, Farnsworth RL (2005) Web-based GIS and spatial decision support system for watershed management. J Hydro 7: 165-174.

18. Rinner C (2003) Web-based spatial decision support: status and research directions. J Geo Info Dec Anal 7: 14-31.

19. Sugumaran R, Meyer J, Davis J (2004) A web-based environmental decision support system (WEDSS) for environmental planning and watershed management. J Geo Sys 6: 1-16.

20. Delft University of Technology (2009) SWAN Cycle III Version 40.72 ABCDE User Manual. Delft, Netherlands.

21. Zhang Y, Sugumaran R, McBroom M, DeGroote J, Kauten RL, et al. (2011) Web-based spatial decision support system and watershed management with a case study. Int J Geosci 2: 195-203. 